the collection to Natal University, and to add a Bantu museum to be specially built in the city.

Miss Campbell has steadily accumulated her possessions for more than twenty-five years. Specializing in the Bantu, their history and customs, her work has primarily been confined to the tribes of the Union, the Rhodesias, and the Protectorates. Recently, however, its scope has been extended to all Bantu tribes south of the Sudan.

The library now contains over 25,000 volumes, ranging from complete collections of the standard anthropological journals to rare first editions of Africana. Miss Campbell is particularly proud of her many volumes of old travel books, some of them in Portuguese and French. Even more impressive, perhaps, is the assembly of original manuscripts. There are, for instance, nearly 2,000 of the Colenso papers, together with those of James Stuart in the original Zulu and English; and Alistair Miller's Swaziland papers. Several valuable files of Shepstone's writings are to be seen, and, not least, Father Bryant's last unpublished work in manuscript.

Besides many comprehensive sets of old newspapers (thirty-one volumes of The Times of Swaziland, for example) the library contains a large number of remarkable old maps, including some showing the whereabouts of tribes in Natal before Shaka's wars of conquest. There are also quantities of original photographs of tribes and historical places, as well as a set of some 120 water-colours of African tribal dress by the artist Barbara Tyrrell. The collection further comprises Bantu handicrafts, pictures by Bantu artists, lithographs, and other old prints. Miss Campbell has always generously encouraged visits from serious students all over the world, to whom she opens the full facilities of her collection and library.

(Communicated by D. H. READER)

\title{
Toponymy and Anthroponymy
}

The fifth International Congress of Onomastic Sciences is to be held in April I955 at Salamanca. The section on 'native languages' will include a paper on 'Un problème d'onomastique africaine: le nom du "père" ", by E. Possoz.

\section{University College Hospital, Ibadan}

The Governor-General of the Federation of Nigeria, Sir John Macpherson, laid the foundation stone of the future teaching hospital of Nigeria at the University College Hospital, Ibadan, on 18 November 1954. It is hoped that the hospital will be opened in 1956; it will be equipped to provide facilities of a standard comparable with those existing in the most modern teaching hospitals of the United Kingdom. The chief purpose of the hospital is to provide clinical training for medical students who receive their earlier training at the University College, Ibadan; it will also include facilities for research in all departments.

\section{Recordings of African Music}

The African Music Society (Roodepoort, Johannesburg) announces the Osborn Awards for the best recordings of African music for 1953. Two hundred and seventy-five entries were received from all over Africa; the judges recommended in awards of 7 guineas each; 9 entries, being highly commended, receive 2 guineas each. This expansion of the original intention to present only a first, second, and third award, and s highly commended, was recommended by the judges in view of the large number of entries, the high standard of performance, and the great diversity of musical styles found in Africa. The successful entries included music from French West Africa, Nigeria, Belgian Congo, Sudan, Uganda, Kenya, Tanganyika, Southern Rhodesia, and Mozambique. Apart from two orchestral items and one tune for is drums, the records were songs with drum, xylophone, zither, or lute accompaniment. 